\title{
Persamaan Empiris Sederhana untuk Memprediksikan Ukuran Partikel dari Enkapsulasi Oleoresin Jahe Merah
}

\author{
Jayanudin Jayanudin ${ }^{a, b}$, Rochmadi Rochmadi ${ }^{a *}$, Moh. Fahrurrozi ${ }^{a}$, Sang Kompiang \\ Wirawan $^{a}$ \\ ${ }^{a}$ Departemen Teknik Kimia, Fakultas Teknik, Universitas Gadjah Mada. Jl. Grafika No. 2 Yogyakarta, \\ 55281, Indonesia \\ ${ }^{b}$ Jurusan Teknik Kimia, Fakultas Teknik, Universitas Sultan Ageng Tirtayasa. Jl. Jenderal Sudirman km.3, \\ Cilegon, 42435, Indonesia \\ * Corresponding author \\ E-mail: rochmadi@ugm.ac.id
}

DOI: 10.20961/alchemy.14.2.17076.178-192

Received 31 December 2017, Accepted 21 January 2018, Published Online 03 September 2018

\begin{abstract}
ABSTRAK
Tujuan penelitian ini adalah menentukan persamaan empiris dari bilangan tak berdimensi untuk memprediksikan ukuran mikrokapsul oleoresin jahe merah. Metode enkapsulasi yang digunakan adalah crosslink emulsi dengan kitosan sebagai penyalut dan glutaraldehyde saturated toluene (GST) sebagai agen crosslink. Oleoresin jahe merah dan kitosan dengan konsentrasi 1, 2, 3 dan 4\% (w/v) diaduk dengan kecepatan 10.000 rpm untuk membentuk emulsi, kemudian dimasukan dalam minyak jagung dan diaduk kembali untuk membentuk emulsi kedua. Sebanyak $10 \mathrm{~mL}$ glutaraldehyde saturated toluene (GST) sebagai agen crosslink ditambahkan secara bertahap. Setelah itu, ditambahkan larutan glutaraldehida $25 \%$ dan terus diaduk selama 2 jam. Mikrokapsul dipisahkan dan dicuci dengan petroleum eter dan heksan, kemudian dikeringkan dalam oven dengan suhu $70{ }^{\circ} \mathrm{C}$. Dengan cara yang sama digunakan untuk membuat mikrokapsul pada kecepatan pengadukan 5.000, 8.000 dan $15.000 \mathrm{rpm}$. Ukuran diameter mikrokapsul dianalisis menggunakan mikroskop digital. Persamaan empiris dari bilangan tak berdimensi Reynolds $(R e)$ dan Ohnesorge $(O h)$ dibuat untuk memprediksikan diameter mikrokapsul. Data dari variabel perubahan konsentrasi kitosan dan kecepatan pengadukan dapat menghasilkan persamaan empiris dari bilangan Reynolds $(R e)$ dan Ohnesorge $(O h)$. Konstanta yang dihasilkan adalah $K=422,06, x=0,37$ dan $y=-0,18$. Berdasarkan perbandingan antara data diameter penelitian dan hasil perhitungan didapat $\%$ kesalahan sebesar $8,05 \%$ untuk pengaruh konsentrasi kitosan dan 7,52\% untuk pengaruh kecepatan pengadukan.
\end{abstract}

Kata kunci: bilangan Ohnesorge $(\mathrm{Oh})$, bilangan Reynolds $(\mathrm{Re})$, enkapsulasi, oleoresin jahe merah

\begin{abstract}
A Simple Empirical Equation for Predicting Particle Size from Encapsulation of Red Ginger Oleoresin. This study aims to determine the empirical equations of the dimensionless number to predict the diameter size of red ginger oleoresin microcapsules. The encapsulation method used is crosslinking emulsion with chitosan as coating and glutaraldehyde saturated toluene (GST) as a crosslinking agent. Red ginger oleoresin and chitosan with concentrations of $1,2,3$ and $4 \%(\mathrm{w} / \mathrm{v})$ were stirred at $10,000 \mathrm{rpm}$ to form emulsions, and then added to the corn oil and stirred again to form a second emulsion. The $10 \mathrm{~mL}$ of glutaraldehyde saturated toluene (GST) as a crosslinking agent was added gradually. After that, a $25 \%$ glutaraldehyde solution was added and stirred for 2 hour. Microcapsules were separated and washed with petroleum ether and hexane, then dried in an oven at a temperature $70{ }^{\circ} \mathrm{C}$. The same step, the microcapsules
\end{abstract}


were made at stirring speed of 5,000; 8,000; and 15,000 rpm. The size of the microcapsule diameter was analyzed using a digital microscope. The empirical equations of the dimensionless numbers Reynolds $(R e)$ and Ohnesorge $(\mathrm{Oh})$ are made to predict the microcapsule diameter. The data from the chitosan concentration change and stirring speeds could produce the empirical equations of the Reynolds and Ohnesorge numbers. The resulting constants were $K=422.06, x=0.37$ dan $y=-0.18$. By comparing the data diameter of the research and calculation results obtained $\%$ error of $8.05 \%$ for the influence of chitosan concentration and $7.52 \%$ for the effect of stirring speed.

Keywords: encapsulation, Ohnesorge number, red ginger oleoresin, Reynold number

\section{PENDAHULUAN}

Oleoresin jahe merah merupakan produk ekstrak dari jahe merah yang mengandung komponen aktif yang dapat digunakan sebagai antioksidan dan antimikroka (Oboh et al., 2012; Yeh et al., 2014). Kelemahan dari oleoresin jahe merah adalah mudah dipengaruhi oleh lingkungan seperti panas, cahaya dan mikroorganisme. Faktor lingkungan tersebut dapat mendegradasi komponen aktif dari oleoresin jahe merah (Shaikh et al., 2006). Oleoresin jahe merah dapat dilindungi dari pengaruh lingkungan dengan enkapsulasi.

Enkapsulasi terdiri dari beberapa metode, seperti spray drying, koaservasi, gelasi ionik, in-situ polimerisasi, crosslink emulsi, dan lain-lain. Pada penelitian ini proses enkapsulasi oleoresin jahe merah menggunakan metode crosslink emulsi. Metode ini melibatkan reaktivitas gugus fungsi amina dari kitosan sebagai penyalut yang bereaksi silang dengan gugus fungsi aldehida sebagai agen crosslink (Mitra and Dey, 2011)

Metode crosslink emulsi melibatkan polimer/biopolymer yang mengandung bahan inti dalam bentuk droplet-droplet kecil, kemudian ditambahkan agen crosslink untuk reaksi crosslink antar rantai molekul kitosan dan langsung dikonversi menjadi mikrokapsul (Manjanna et al., 2010; Dhakar et al., 2012). Kelebihan metode crosslink emulsi adalah dapat digunakan untuk bahan yang saling larut, tidak saling larut, cair atau padat dan juga dapat digunakan untuk menghasilkan ukuran mikropartikel dan nanopartikel (Manjanna et al., 2010; Mitra and Dey 2011).

Metode crosslink emulsi digunakan untuk enkapsulasi ibuprofen dan menghasilkan yield yang cukup besar yaitu 99\% dan mikrokasul yang dihasilkan berbentuk geometris bola dengan permukaan mikrokapsul yang halus (Ofokansi et al., 2013). Penelitian lain yang menggunakan crosslink emulsi adalah Campos et al. (2013). Penelitian yang dilakukan adalah membuat mikropartikel dari gabungan antara kitosan dengan poli vinil alkohol (PVA) dengan glutaraldehyde saturated toluene (GST) sebagai agen crosslink dalam medium minyak jagung. Hasil yang diperoleh adalah mikropartikel berbentuk bulat dengan permukaan yang halus. Berdasarkan uji toksisitas menunjukkan tidak ada efek buruk pada 
kelangsungan hidup sel. Hal ini dimungkinan akibat dari reaksi silang yang dilakukan. Pada penelitian ini modifikasi metode crosslink emulsi yang dilakukan adalah dengan emulsi ganda sehingga bentuk emulsinya berupa oil in water in oil (O/W/O).

Produk proses enkapsulasi berupa partikel-partikel padatan dengan berbagai ukuran. Ukuran partikel dari enkapsulasi tergantung pada ukuran droplet emulsi yang dibuat pada awal proses enkapsulasi. Ukuran droplet emulsi ini dapat berpengaruh pada ukuran mikrokapsul. Untuk memprediksikan ukuran droplet emulsi dapat menggunakan bilangan tak berdimensi yang dikembangkan oleh Zlokarnik (2001). Pada penelitian yang dilaporkan oleh Dalmoro et al. (2013), prediksi ukuran droplet pada proses mikroenkapsulasi dengan metode atomisasi ultrasonik menggunakan hubungan bilangan tak berdimensi Reynolds $(R e)$, bilangan Weber $(W e)$ dan bilangan Ohnesorge $(O h)$. Bilangan Weber $(W e)$ dan Ohnesorge $(\mathrm{Oh})$ berkaitan dengan tegangan antar muka, sedangkan bilangan Reynolds (Re) berkaitan dengan gaya inersia dan viskositas (Dalmoro et al., 2013).

Bilangan tak berdimensi digunakan untuk memfasilitasi peningkatan kapasitas (scale-up) dari hasil yang diperoleh dengan kondisi nyata (Zlokarnik, 2001). Permasalahan yang timbul adalah ketika hasil dari skala laboratorium menjadi skala industri membutuhkan parameter seperti permindahan massa, perpindahan panas dan momentum. Permasalahan ini dapat disederhanakan dengan analisis bilangan tak berdimensi. Sebagai contoh bilangan Reynolds digunakan untuk menentukan bentuk suatu aliran laminar atau turbulen dan masih banyak bilangan tak berdimensi lain untuk menentukan fenomena-fenomena suatu proses.

Ukuran droplet emulsi dipengaruhi oleh kecepatan pengadukan, viskositas dan tegangan antar muka. Dengan mengasumsikan ukuran droplet emulsi sama dengan ukuran partikel enkapsulasi, maka bilangan tak berdimensi dapat digunakan untuk memprediksikan ukuran partikel dari produk enkapsulasi. Pada penelitian ini bilangan tak berdimensi yang digunakan adalah bilangan Reynolds $(R e)$ untuk mengetahui perubahan kecepatan dan viskositas larutan terhadap ukuran mikrokapsul, bilangan Ohnesorge (Oh) untuk menentukan pengaruh tegangan permukaan terhadap ukuran partikel mikrokapsul. Penggabungan dari ketiga bilangan tak berdimensi tersebut dapat membentuk persamaan empiris yang dapat digunakan untuk menentukan ukuran mikrokapsul. Tujuan penelitian ini adalah menentukan persamaan empiris dari bilangan tak berdimensi untuk memprediksikan ukuran diameter mikrokapsul oleoresin jahe merah dan dibandingkan dengan data hasil penelitian. 


\section{METODE PENELITIAN}

Bahan yang digunakan dalam penelitian ini meliputi: Oleoresin jahe merah berasal Lansida Grup, glutaraldehida 25\% dari Merck, toluen teknis dari CV. Tri Jaya Dinamika, kitosan dari PT. Biotech Surindo dengan derajat deasetilasi (DD) $=87,2 \%$ dan viskositas 37,10 cps, minyak jagung merk CCO diproduksi oleh CV. Surya Agung, asam asetat glasial $100 \%$ dari Merck, petroleum eter teknis dan n-heksan teknis dari CV. Labora. Peralatan penelitian yang digunakan adalah homogenizer IKAWerk Ultra-Turrax, International Clinical Benchtop Centrifuge \& Swing Rotor, Oven Kirin model KBO-90M, dan microskop digital Dino-Lite.

\section{Proses Enkapsulasi Oleoresin Jahe Merah dengan Metode Crosslink Emulsi}

Proses enkapsulasi dengan teknik crosslink emulsi ini merupakan modifikasi dari penelitian yang dilakukan oleh Jameela and Jayakrishnan (1995); Campos et al. (2013) dan Ofokansi et al. (2013). Sebanyak 4 gram oleoresin dimasukan dalam larutan kitosan dengan konsentrasi 1, 2, 3 dan 4\% (w/v). Campuran tersebut diaduk selama 30 menit menggunakan homogenizer dengan kecepatan $10.000 \mathrm{rpm}$ untuk menghasilkan emulsi oil in water $(\mathrm{O} / \mathrm{W})$. Setelah emulsi pertama terbentuk dimasukkan dalam $150 \mathrm{~mL}$ minyak jagung dan diaduk kembali dengan kecepatan yang sama selama 1 jam untuk menghasilkan emulsi kedua oil in water in oil (O/W/O). Setelah selesai pengadukan, kemudian ditambahkan $10 \mathrm{~mL}$ agen crosslink yaitu glutaraldehyde saturated toluene (GST) yang dibuat dari pencampuran antara glutaraldehida $25 \%$ dengan toluen dengan perbandingan volume yang sama. Campuran tersebut diaduk menggunakan overhead stirrer IKA dengan kecepatan 500 rpm selama 3 jam. Campuran tersebut didiamkan selama semalam, kemudian diambil lapisan paling atas sebagai glutaraldehyde saturated toluene (GST). Penambahan agen crosslink dilakukan secara bertahap yaitu setiap 15 menit sampai volume GST habis. Setelah penambahan GST selesai, campuran masih terus diaduk selama 15 menit kemudian ditambahkan larutan glutaraldehida $25 \%$ untuk lebih mengeraskan penyalut dan terus diaduk selama 2 jam. Mikrokapsul yang terbentuk dipisahkan menggunakan centrifuge (International Clinical Benchtop Centrifuge \& Swing Rotor), kemudian mikrokapsul dicuci menggunakan petroleum eter dilanjutkan dengan dengan n-heksan. Mikrokapsul oleoresin jahe merah yang dihasilkan dikeringkan dalam oven pada suhu $70{ }^{\circ} \mathrm{C}$. Prosedur yang sama digunakan untuk membuat mikrokapsul oleoresin jahe merah menggunakan konsentrasi kitosan 2\% dan volume GST $10 \mathrm{~mL}$ pada variasi kecepatan pengadukan yaitu $5.000 \mathrm{rpm}$, $8.000 \mathrm{rpm}$ dan $15.000 \mathrm{rpm}$. 


\section{Analisis Bahan dan Produk Penelitian}

\section{Analisis bahan baku penelitian}

Untuk dapat menghitung bilangan Reynolds $(R e)$ dan bilangan Ohnesorge $(O h)$ sebagai bilangan tak berdimensi membutuhkan analisis dari bahan baku yang digunakan seperti analisis viskositas larutan kitosan menggunakan viskometer Ostwald, densitas larutan kitosan menggunakan piknometer, dan analisis tegangan antar muka (larutan kitosan-minyak jagung) menggunakan tensiometer Kruss.

\section{Analisis ukuran mikrokapsul oleoresin jahe merah}

Analisis ukuran mikrokapsul yang dihasilkan dilakukan menggunakan mikroskope digital Dino-Lite dengan perbesaran 500x. kalibrasi ukuran partikel dapat dilakukan dengan membandungkan ukuran diameter serabut kawat riil dengan ukuran dari mikroskop digital, kemudian dibuat sebagai faktor koreksi. Ukuran diameter rata-rata mikrokapsul dapat ditentukan dengan Dino-Lite Digital Microscope. Diameter mikrokapsul ditentukan dengan mengobservasi 100 droplet (mikrokapsul) untuk dihitung diameter rata-rata. Persamaan 1 yang digunakan untuk menentukan diameter rata-rata.

$$
\bar{d}=\sum_{i=n}^{n} \frac{d_{i}}{N}
$$

Keterangan:

$d_{i} \quad=$ diameter tiap droplet

$\mathrm{N} \quad=$ total jumlah mikrokapsul yang dihitung

$\bar{d} \quad=$ jumlah diameter rata-rata.

\section{Model persamaan untuk memprediksikan ukuran partikel}

Persamaan yang digunakan untuk memprediksikan ukuran mikrokapsul oleoresin jahe merah merupakan korelasi antara bilangan Weber $(W e)$, bilangan Reynolds $(R e)$ dan bilangan Ohnesorge $(O h)$. Korelasi secara empiris dapat dilihat pada persamaan 2, sedangkan bilangan Reynolds $(\mathrm{Re})$, Weber $(\mathrm{We})$, dan Ohnesorge $(\mathrm{Oh})$ ditentukan dengan persamaan 3, 4, dan 5 .

$$
\begin{aligned}
& d_{\text {avg }}=K(O h)^{x}(R e)^{y} \\
& R e=\frac{\rho \cdot v \cdot d_{p}}{\mu} \\
& W e=\frac{\rho \cdot v^{2} \cdot d_{p}}{\sigma} \\
& O h=\frac{\sqrt{W e}}{R e}
\end{aligned}
$$

Dimana,

$$
d_{\text {avg }}=\text { diameter rata-rata mikrokapsul }(\mu \mathrm{m})
$$




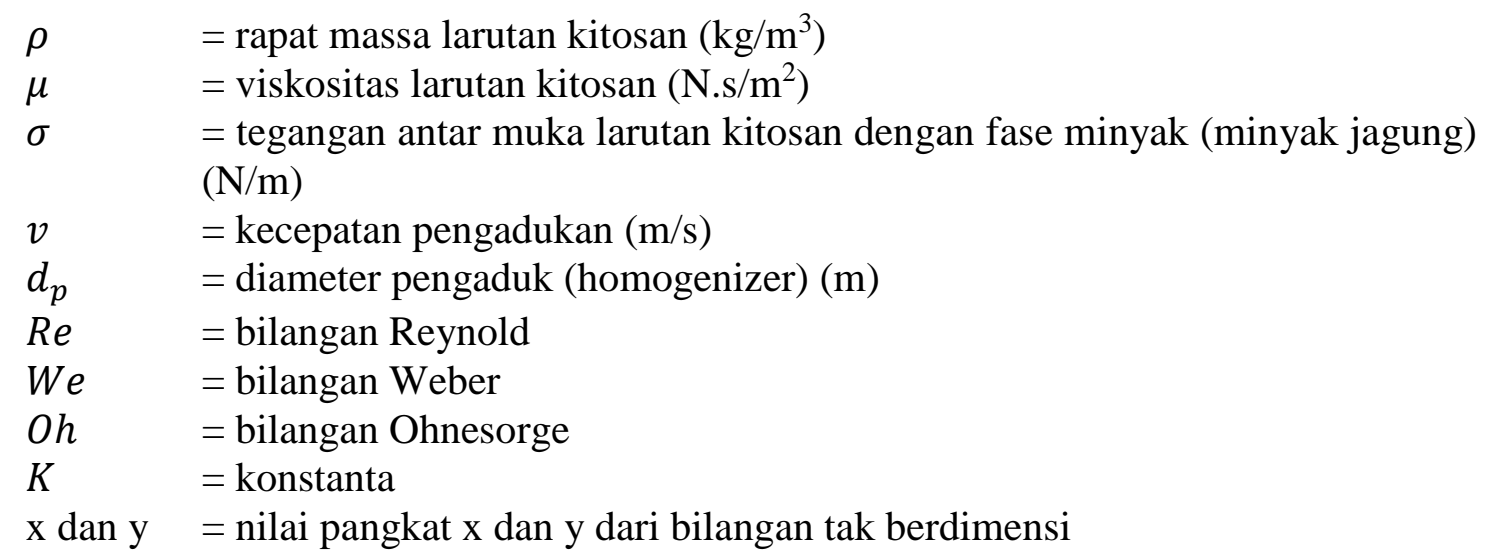

Tetapan seperti nilai $\mathrm{K}$, $\mathrm{x}$ dan y pada persamaan 2 dapat ditentukan dengan cara kuadrat terkecil (least squares). Penentukan nilai tetapan pada persamaan 2, dilakukan dengan menggunakan persamaan 6,7 , dan 8 .

$$
\log d_{\text {avg }}=\log K+x \log (O h)+y \log (R e)
$$

Dengan menyederhanakan persamaan 6 menjadi :

$$
\mathrm{P}=\mathrm{C}_{0}+\mathrm{C}_{1} \cdot \mathrm{Q}+\mathrm{C}_{2} \mathrm{R}
$$

Untuk menentukan nilai $\mathrm{C}_{0}, \mathrm{C}_{1}$ dan $\mathrm{C}_{2}$ digunakan persamaan 8 .

$$
\begin{aligned}
& N C_{0}+C_{1} \sum Q_{i}+C_{2} \sum R_{i}=\sum P_{i} \\
& N \sum Q_{i}+C_{1} \sum Q_{i}^{2}+C_{2} \sum R_{i} Q_{i}=\sum Q_{i} P_{i} \\
& N \sum R_{i}+C_{1} \sum R_{i} Q_{i}+C_{2} \sum R_{i}^{2}=\sum R_{i} P_{i} \\
& \text { Nilai } C_{0}=K, C_{1}=x \text {, dan } C_{2}=y \text { dapat ditentukan menggunakan matriks. }
\end{aligned}
$$

\section{HASIL DAN PEMBAHASAN}

\section{Hasil Analisis Bahan Baku}

Analisis bahan baku ini digunakan untuk menentukan besarnya bilangan tak berdimensi yaitu untuk bilangan Reynold dan Weber. Hasil dari analisis bahan baku dapat dilihat pada Tabel 1 .

Tabel 1. Hasil analisis viskositas, densitas dan tegangan antar muka.

\begin{tabular}{ccccc}
\hline No & $\begin{array}{c}\text { Konsentrasi } \\
\text { kitosan }(\% \mathbf{w} / \mathbf{v})\end{array}$ & $\begin{array}{c}\text { Viskostas } \\
(\eta) \\
\left(\mathbf{N . s} / \mathbf{m}^{2}\right)\end{array}$ & $\begin{array}{c}\text { Densitas }(\rho) \\
\left(\mathbf{k g} / \mathbf{m}^{\mathbf{3}}\right)\end{array}$ & $\begin{array}{c}\text { Tegangan antar muka } \\
(\text { larutan kitosan-minyak } \\
\text { jagung) }(\boldsymbol{\sigma})(\mathbf{N} / \mathbf{m})\end{array}$ \\
\hline 1 & 1 & 0,0942 & 996,8 & 0,00062 \\
2 & 2 & 0,1118 & 998,3 & 0,00058 \\
3 & 3 & 0,1329 & 1003,2 & 0,00055 \\
4 & 4 & 0,1411 & 1004,6 & 0,00033 \\
\hline
\end{tabular}

Pada Tabel 1 menunjukkan hasil analisis bahan baku yaitu larutan kitosan dengan konsentrasi 1-4\%. Peningkatan konsentrasi kitosan akan meningkatkan viskositas dan 
densitasnya. Pengukuran viskositas dan densitas ini digunakan untuk menghitung bilangan Reynolds (Re), Weber (We) dan Ohnesorge (Oh). Kedua bilangan tak berdimensi berhubungan dengan pembentukan ukuran droplet emulsi. Bilangan Reynolds (Re) digunakan untuk mengidentifikasikan jenis aliran yaitu aliran turbulen dan laminar. Peningkatan kecepatan aliran akan meningkatkan bilangan Reynolds $(R e)$ dan efeknya akan meningkatkan pemecahan ukuran droplet emulsi menjadi lebih kecil (Anisa and Nour, 2010). Bilangan tak berdimensi Weber (We) berhubungan dengan tegangan antar muka antara air dan minyak, kemudian bilangan ini dirubah menjadi bilangan Ohnesorge $(O h)$. Tegangan antar muka ini sangat berhubungan dengan kestabilan emulsi. Penggunaan surfaktan dalam pembuatan emulsi bertujuan untuk mengurangi tegangan antar muka sehingga emulsi lebih stabil (Kamarudin et al., 2010).

Pada Tabel 1 menunjukkan bahwa semakin tinggi konsentrasi kitosan, tegangan antar permukaan semakin kecil. Tegangan antar muka berkaitan dengan kestabilan droplet emulsi, kenaikan tegangan antar muka dapat meningkatkan kestabilan droplet emulsi. Konsentrasi kitosan dapat meningkatkan viskositas dan densitas sehingga akan mempengaruhi aktifitas reaksi crosslink antara gugus amin dari kitosan dengan gugus aldehida dari GST. Peningkatan konsentrasi kitosan dapat meningkatkan ukuran mikrokapsul karena dinding mikrokapsul yang dihasilkan lebih tebal dan padat.

\section{Menentukan persamaan empiris bilangan tak berdimensi}

Enkapsulasi merupakan suatu proses perlindungan obat atau bioaktif dari pengaruh lingkungan. Fungsi lain adalah untuk mengontrol pelepasan obat (controlled drug release). Ukuran mikrokapsul berkaitan dengan luas areanya, sehingga akan mempengaruhi proses rilis obatnya. Persamaan empiris ini digunakan untuk memprediksikan ukuran mikrokapsul yang berguna untuk menentukan diameter mikrokapsul yang diinginkan sesuai dengan kebutuhan rilis obat.

Parameter yang mempengaruhi ukuran partikel dari proses enkapsulasi seperti kecepatan pengadukan pada waktu pembentuk emulsi, konsentrasi penyalut, tegangan antar muka, dan lain-lain. Parameter-parameter tersebut dapat dihubungkan dengan beberapa bilangan tak berdimensi dan dapat disatukan menjadi suatu persamaan empiris untuk memprediksikan ukuran partikel. Pada Tabel 2 menunjukkan parameter-parameter yang digunakan untuk menentukan persamaan empiris dari bilangan tak berdimensi. 
Tabel 2. Parameter untuk menentukan persamaan empiris bilangan tak berdimensi.

\begin{tabular}{cccccccc}
\hline No & $\begin{array}{c}\text { Kecepatan } \\
\text { pengadukan } \\
\text { dan } \\
\text { konsentrasi } \\
\text { kitosan }\end{array}$ & $\begin{array}{c}\text { Densitas } \\
(\boldsymbol{\rho}) \\
\left(\mathbf{k g} / \mathbf{m}^{3}\right)\end{array}$ & $\begin{array}{c}\text { Viskositas } \\
(\boldsymbol{\mu})\left(\mathbf{N s} / \mathbf{m}^{2}\right)\end{array}$ & $\begin{array}{c}\text { Tegangan } \\
\text { antar } \\
\mathbf{m u k a}(\boldsymbol{\sigma}) \\
\mathbf{( N / m})\end{array}$ & $\begin{array}{c}\text { Diameter } \\
\text { pengaduk } \\
(\mathbf{m})\end{array}$ & $\begin{array}{c}\text { Kecepatan } \\
\text { pengadukan } \\
(\mathbf{m} / \mathbf{s})\end{array}$ & $\begin{array}{c}\text { Diameter } \\
\text { mikrokapsul } \\
(\mathbf{d a v g})(\boldsymbol{\mu m})\end{array}$ \\
\hline 1 & kitosan 1\% & 996,8 & 0,094 & 0,00062 & 0,015 & 7,85 & 136,301 \\
2 & kitosan 2\% & 998,3 & 0,112 & 0,00058 & 0,015 & 7,85 & 127,657 \\
3 & kitosan 3\% & 1003,2 & 0,133 & 0,00055 & 0,015 & 7,85 & 147,978 \\
4 & kitosan 4\% & 1004,6 & 0,141 & 0,00033 & 0,015 & 7,85 & 167,621 \\
5 & $5.000 \mathrm{rpm}$ & 998,3 & 0,112 & 0,00058 & 0,015 & 3,93 & 130,330 \\
6 & $\mathbf{8 . 0 0 0 ~ r p m}$ & 998,3 & 0,112 & 0,00058 & 0,015 & 6,28 & 129,009 \\
7 & $10.000 \mathrm{rpm}$ & 998,3 & 0,112 & 0,00058 & 0,015 & 7,85 & 127,657 \\
8 & $15.000 \mathrm{rpm}$ & 998,3 & 0,112 & 0,00058 & 0,015 & 11,78 & 96,148 \\
\hline
\end{tabular}

Berdasarkan persamaan 1-7 dan data dari Tabel 2 dapat dihasilkan konstanta-konstanta seperti $K=422,06, x=0,37$ dan $y=-0,18$. Berdasarkan konstanta yang dihasilkan, maka persamaan 2 menjadi persamaan 9.

$$
d_{\text {avg }}=422,06(O h)^{0,37}(R e)^{-0,18}
$$

Persamaan 9 ini yang digunakan untuk menghitung atau memprediksikan ukuran mikrokapsul oleoresin jahe merah dan membandingkannya dengan ukuran mikrokapsul hasil penelitian berdasarkan pengaruh konsentrasi kitosan dan kecepatan pengadukan.

\section{Pengaruh konsentrasi kitosan terhadap prediksi ukuran mikrokapsul oleoresin jahe merah}

Pada tahap awal proses enkapsulasi adalah pembentukan emulsi antara larutan kitosan dengan oleoresin kemudian dilanjutkan dengan pembentukan emulsi kedua dengan memasukan emulsi pertama dalam minyak jagung. Ukuran droplet yang dihasilkan pada pembentukan emulsi akan berpengaruh pada ukuran mikrokapsul yang dihasilkan. Pada tahap ini konsentrasi yang digunakan adalah 1-4\% (w/v) dengan kecepatan pengadukan 10.000 rpm. Pada Tabel 3 menunjukkan diameter rata-rata mikrokapsul berdasarkan perubahan konsentrasi kitosan, serta hasil prediksi ukuran partikel hasil perhitungan menggunakan persamaan 9. Persen kesalahan digunakan untuk membandingkan diameter mikrokapsul hasil penelitian dan perhitungan.

Dari persamaan 9 yang telah diperoleh, maka dilakukan perhitungan untuk menentukan prediksi nilai diameter rata-rata mikrokapsul ( $\mathrm{d}_{\mathrm{avg}}$, hitung), kemudian dibandingkan dengan nilai diameter rata-rata dari data penelitian $\left(\mathrm{d}_{\mathrm{avg}}\right.$, data). Gambar 1 berikut ini adalah perbandingan antara ukuran diameter rata-rata hasil prediksi dari persamaan 8 dengan data penelitian. 
Tabel 3. Perubahan konsentrasi kitosan terhadap diameter rata-rata mikrokapsul dan bilangan tak berdimensi

\begin{tabular}{ccccc}
\hline No & $\begin{array}{c}\text { Konsentrasi } \\
\text { kitosan }(\% \\
\text { w/v) }\end{array}$ & $\begin{array}{c}\text { Diameter rata-rata } \\
\left(\mathbf{d}_{\mathbf{A B}}\right) \text { data } \\
\text { penelitian }(\boldsymbol{\mu m})\end{array}$ & $\begin{array}{c}\text { Diameter rata-rata } \\
\left(\mathbf{d}_{\text {avg }}\right) \text { hasil } \\
\text { perhitungan }(\boldsymbol{\mu m})\end{array}$ & $\begin{array}{c}\% \\
\text { Kesalahan }\end{array}$ \\
\hline 1 & 1 & 136,301 & 113,465 & 20,13 \\
2 & 2 & 127,657 & 126,248 & 1,12 \\
3 & 3 & 147,978 & 140,065 & 5,65 \\
4 & 4 & 167,621 & 159,157 & 5,32 \\
\hline
\end{tabular}

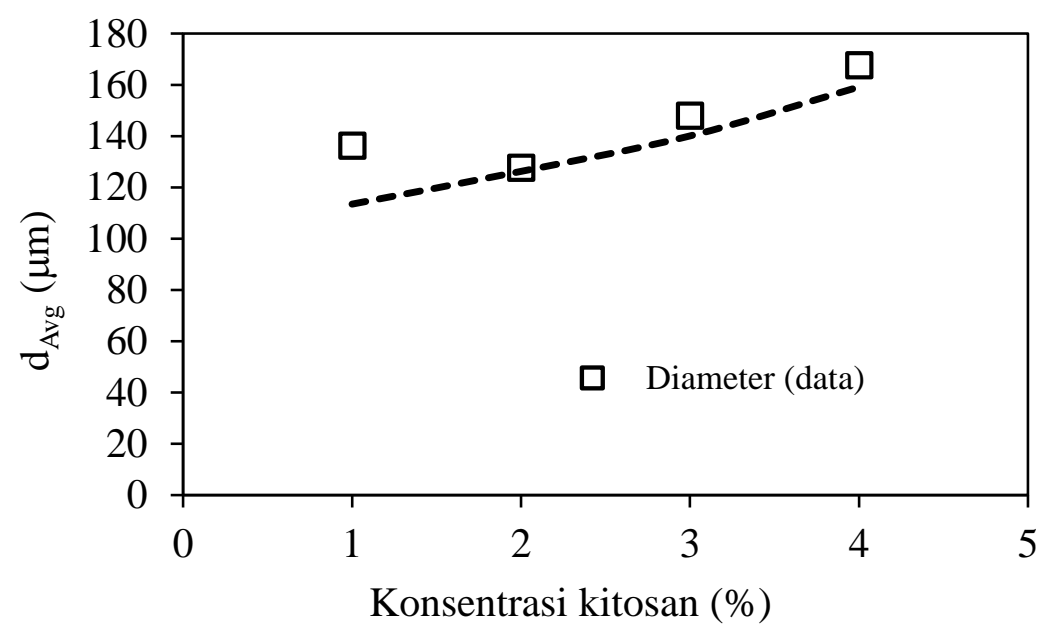

Gambar 1. Perbandingan diameter mikrokapsul rata-rata hitung $\left(\mathrm{d}_{\mathrm{avg}}\right.$, hitung $)$ dan data $\left(\mathrm{d}_{\mathrm{Avg}}\right.$,data $)$ berdasarkan perubahan konsentrasi kitosan.

Persamaan 9 terlihat bahwa bilangan Ohnesorge berpengaruh pada ukuran diameter mikrokapsul. Hal ini ditunjukkan pada pangkat bilangan Ohnesorge $(O h)(x)$ lebih besar dibandingkan dengan pangkat bilagan Reynolds $(R e)(\mathrm{y})$. Bilangan Ohnesorge berhubungan dengan viskositas dan tegangan antar muka. Hasil perhitungan dengan menggunakan persamaan 9 menunjukkan bahwa selisih antara diameter rata-rata data dengan hasil perhitungan menghasilkan \% kesalahan rata-rata cukup kecil yaitu sekitar 8,05\%. Pada Gambar 2 menunjukkan contoh analisis diameter mikrokapsul menggunakan mikroskop digital.

Diameter rata-rata hasil perhitungan menggunakan persamaan 9 yang terdapat pada Tabel 3 menunjukkan bahwa semakin besar konsentrasi kitosan, maka semakin besar ukuran diameter rata-ratanya. Berbeda dengan hasil penelitian pada kitosan dengan konsentrasi $1 \%$, ukuran diameter rata-rata mikrokapsul lebih besar dibandingkan dengan kitosan $2 \%$. Seperti yang ditunjukkan pada Gambar 2D, diameter mikrokapsulnya lebih besar dibandingkan dengan Gambar 2C. Penyebab yang mungkin terjadi adalah sewaktu proses emulsi, droplet yang dihasilkan belum stabil sehingga selama proses enkapsulasi droplet-droplet tersebut saling menempel kembali untuk membentuk droplet yang lebih besar. Ukuran diameter pada 
konsentrasi kitosan $4 \%$ lebih besar dibandingkan dengan yang lain. Hal ini berkaitan dengan besarnya konsentrasi kitosan menyebabkan dinding mikrokapsul setelah terjadi crosslink dengan GST menghasilkan dinding yang lebih tebal dan kaku sehingga diameter mikrokapsul lebih besar.

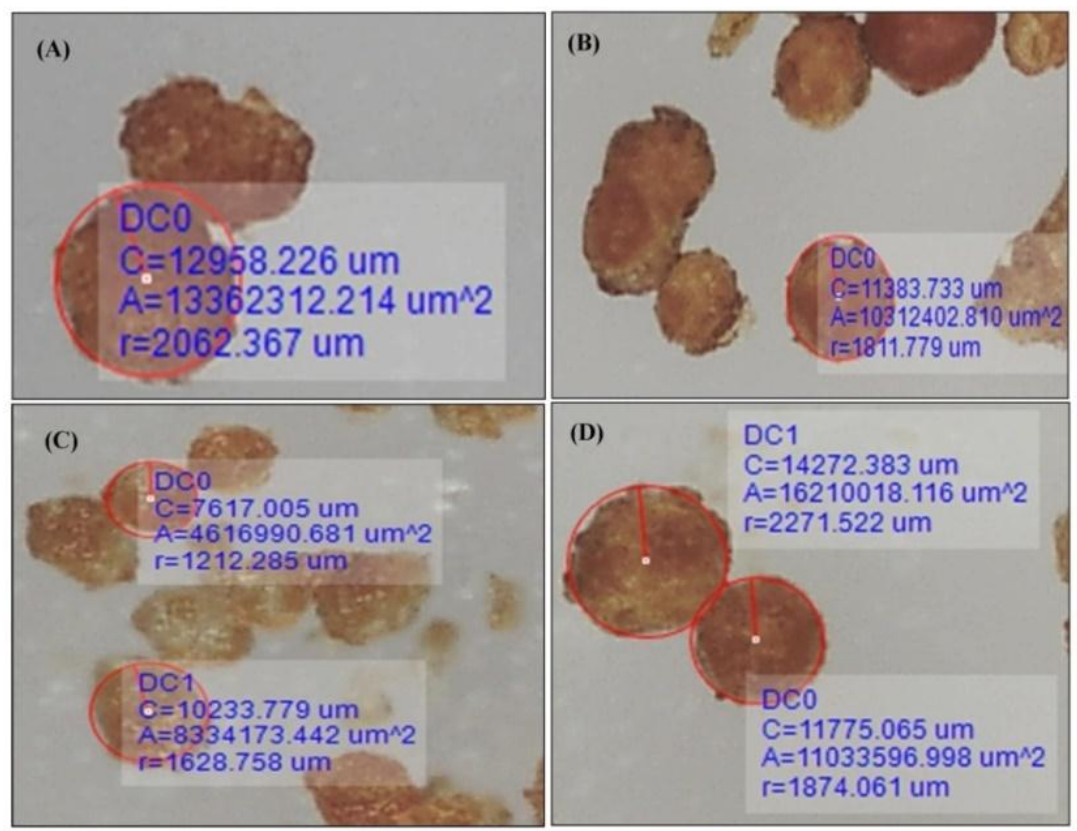

Gambar 2. Perbandingan ukuran mikrokapsul menggunakan mikroskop digital. Konsentrasi kitosan (A) 4\%, (B) 3\%, (C) $2 \%$ dan (D) $1 \%$.

\section{Pengaruh kecepatan pengadukan terhadap prediksi ukuran mikrokapsul oleoresin jahe merah}

Kecepatan pengadukan merupakan salah satu faktor yang menentukan ukuran droplet dan kestabilan emulsi. Proses pengadukan akan berpengaruh pada besarnya tegangan antar muka, semakin cepat pengadukan maka tegangan antar muka akan semakin kecil sehingga ukuran droplet emulsi yang dihasilkan lebih kecil (Sari and Lestari, 2015). Ukuran droplet emulsi ini diasumsikan sama dengan ukuran mikrokapsul.

Pada penelitian ini pengaruh kecepatan pengadukan terhadap ukuran diameter mikrokapsul dilakukan pada konsentrasi kitosan tetap yaitu 2\%. Pada Tabel 4 menunjukkan perbandingan antara diameter rata-rata hasil penelitian dengan hasil perhitungan berdasarkan perubahan kecepatan pengadukan.

Persamaan 9 digunakan untuk menentukan persamaan empiris dari pengaruh kecepatan pengadukan. Data penelitian menunjukkan bahwa peningkatan kecepatan pengadukan dapat menurunkan ukuran mikrokapsul. Hasil yang sama juga ditunjukkan melalui prediksi dengan perhitungan menggunakan persamaan 9, hasilnya dapat dilihat pada Tabel 4. Diameter rata-rata hasil perhitungan menunjukkan peningkatan kecepatan 
pengadukan dapat menurunkan ukuran mikrokapsul. Kecepatan pengadukan dapat menurunkan tegangan antar muka, sehingga akan mempermudah terbentuknya dropletdroplet dan meningkatkan kestabilannya. Kecepatan pengadukan berpengaruh pada nilai Reynolds $(R e)$, semakin tinggi kecepatan pengadukan akan meningkatkan kecepatan Reynolds $(R e)$. Pada persamaan 9 menunjukkan bahwa nilai pangkat yang negatif, sehingga dengan semakin tingginya nilai bilangan Reynolds $(R e)$ akan menurunkan diameter partikel.

Tabel 4. Pengaruh kecepatan pengadukan terhadap ukuran mikrokapsul.

\begin{tabular}{ccccc}
\hline No & $\begin{array}{c}\text { Kecepatan } \\
\text { pengadukan } \\
(\mathbf{r p m})\end{array}$ & $\begin{array}{c}\text { Diameter rata- } \\
\text { rata }\left(\mathbf{d}_{\text {avg }}\right) \text { data } \\
\text { penelitian }(\boldsymbol{\mu m})\end{array}$ & $\begin{array}{c}\text { Diameter rata- } \\
\text { rata }\left(\mathbf{d}_{\text {avg }}\right) \text { hasil } \\
\text { perhitungan }(\boldsymbol{\mu m})\end{array}$ & $\begin{array}{c}\% \\
\text { Kesalahan }\end{array}$ \\
\hline 1 & 5.000 & 130,330 & 143,336 & 9,07 \\
2 & 8.000 & 129,009 & 131,518 & 1,91 \\
3 & 10.000 & 127,657 & 126,248 & 1,12 \\
4 & 15.000 & 96,148 & 117,195 & 17,96 \\
\hline
\end{tabular}

Pada Gambar 3 menunjukkan perbandingan antara diameter rata-rata mikrokapsul hasil perhitungan menggunakan persamaan 9 dengan diameter rata-rata dari data penelitian. Penyimpangan terbesar terjadi pada kecepatan pengadukan $15.000 \mathrm{rpm}$ dengan \% kesalahan sebesar 17,96\%. Diameter rata-rata mikrokapsul dari hasil penelitian lebih kecil dibandingkan dengan hasil perhitungan. Pada pengadukan kecepatan tinggi terjadi perubahan suhu pada proses pembuatan emulsi. Perubahan suhu dapat menurunkan viskositas larutan sehingga dapat menurunkan ukuran droplet emulsi.

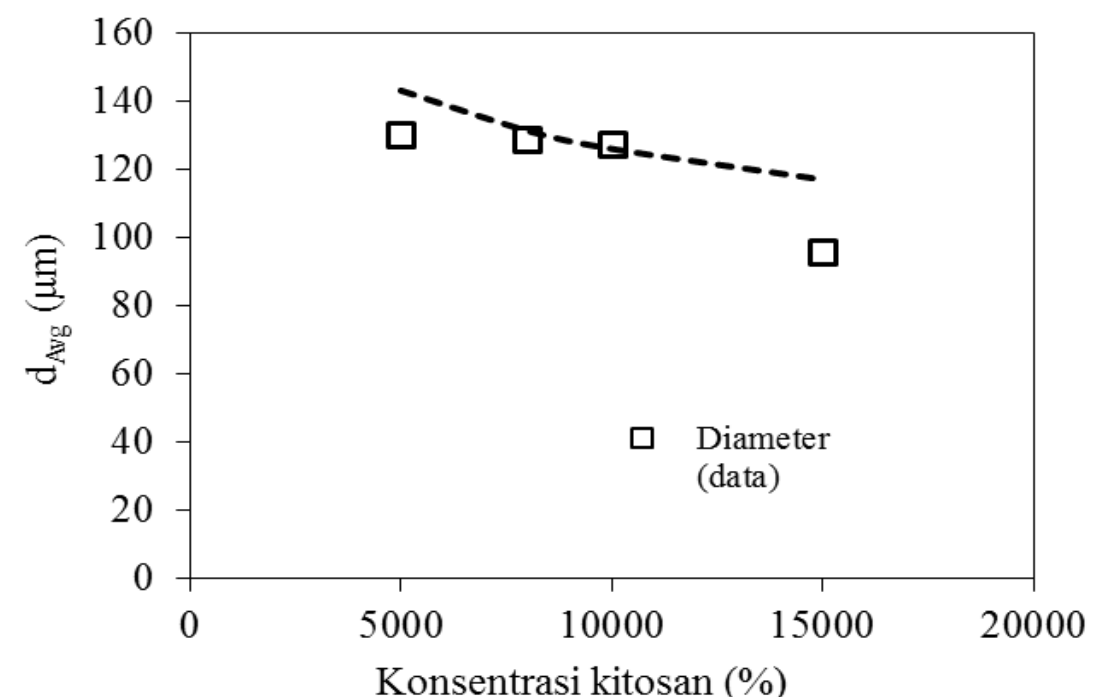

Gambar 3. Pengaruh perubahan kecepatan pengadukan pada diameter mikrokapsul ratarata hitung $\left(\mathrm{d}_{\mathrm{avg}}\right.$, hitung $)$ dan data $\left(\mathrm{d}_{\mathrm{Avg}}\right.$, data $)$.

Analisis bilangan tak berdimensi dengan menghasilkan suatu persamaan empiris digunakan untuk memprediksikan ukuran droplet yang nantinya dijadikan sebagai acuan dalam menentukan ukuran mikrokapsul. Hasil persamaan empiris dari bilangan tak 
berdimensi Reynolds (Re) dan Ohnesorge (Oh), hasil perhitungannya dibandingkan dengan data penelitian dan menunjukkan \% kesalahan yang kecil. Hal ini menunjukkan bahwa persamaan empiris yang dihasilkan dapat digunakan untuk memprediksikan ukuran mikrokapsul oleoresin jahe merah.

Dari Tabel 5 dapat dilihat bahwa penelitian-penelitian yang telah dilakukan mengenai prediksi ukuran droplet yang menghubungan bilangan tak berdimensi dan dibandingkan dengan hasil dari penelitian ini. Kebanyak penelitian yang sudah dilakukan menggunakan metode atomisasi ultrasonik. Kelebihan dari metode atomisasi ultrasonik adalah mampu menghasilkan droplet yang lebih kecil. dengan meningkatkan frekuensi akan mengurangi ukuran droplet (Rajan and Pandit, 2001).

Tabel 5. Perbandingan persamaan yang memprediksikan ukuran droplet emulsi.

\begin{tabular}{|c|c|c|c|}
\hline No & Persamaan empiris & Metode & Pustaka \\
\hline 1 & $d_{p}=0,34\left(\frac{8 \cdot \pi \cdot \sigma}{\rho \cdot f^{2}}\right)^{1 / 3}$ & $\begin{array}{l}\text { Atomisasi } \\
\text { ultrasonic }\end{array}$ & (Lang, 1962) \\
\hline 2 & $d_{p}=31,7\left(\frac{\sigma}{\rho}\right)^{0,354} \eta^{0,303} Q^{0,139}$ & $\begin{array}{l}\text { Cairan } \\
\text { berkecepatan } \\
\text { tinggi }\end{array}$ & (Mochida, 1978) \\
\hline 3 & $d_{p}=\left(\frac{\pi \cdot \sigma}{\rho \cdot f^{2}}\right)^{0,33}\left[1+A \cdot(W e)^{0,22} \cdot(O h)^{0,166} \cdot\left(I_{N}\right)^{-0,0277}\right]$ & $\begin{array}{l}\text { Atomisasi } \\
\text { ultrasonic }\end{array}$ & $\begin{array}{l}\text { (Rajan and Pandit, } \\
\text { 2001) }\end{array}$ \\
\hline 4 & $d_{p}=0,058\left(\frac{\pi \cdot \sigma}{\rho \cdot f^{2}}\right)^{0,33}(W e)^{0,151}(O h)^{0,192} \cdot\left(I_{N}\right)^{-0,02}$ & $\begin{array}{l}\text { Atomisasi } \\
\text { ultrasonic }\end{array}$ & (Barba et al., 2009) \\
\hline 5 & $d_{\text {avg }}=422,06(O h)^{0,37}(R e)^{-0,18}$ & $\begin{array}{l}\text { Pengadukan } \\
\text { berkecepatan } \\
\text { tinggi }\end{array}$ & Hasil penelitian ini \\
\hline
\end{tabular}

Penggunaan bilangan tak berdimensi bersifat umum, tidak hanya digunakan untuk menentukan ukuran partikel dari mikrokapsul. Bilangan Reynolds ( $R e$ ) dapat juga digunakan untuk menganalisis proses perpindahan massa pada tangki perpengaduk atau proses lain yang berkaitan dengan perubahan kecepatan. Analisis bilangan tak berdimensi ini dibutuhkan untuk proses perancangan alat atau proses. Fungsi lain adalah digunakan untuk meningkatkan kapasitas (scale-up) suatu proses.

Tabel 5 menunjukkan beberapa analisis bilangan tak berdimensi menjadi sutau persamaan empiris untuk memprediksikan ukuran droplet. Pada penelitian ini pembentukan emulsi dilakukan dengan menggunakan homogenizer, hasil yang diperoleh sudah cukup baik yaitu mampu menghasilkan ukuran diameter mikrokapsul yang kecil. Peningkatan kecepatan pengadukan homogenizer mampu menghasilkan ukuran diameter mikrokapsul yang semakin kecil. 


\section{KESIMPULAN}

Pada penelitian ini difokuskan pada pengaruh konsentrasi kitosan dan kecepatan pengadukan terhadap ukuran diameter mikrokapsul. untuk memprediksikan ukuran diameter mikrokapsul dibuat persamaan empiris dari bilangan tak berdimensi Ohnesorge $(O h)$ dan Reynold $(R e)$. Persamaan yang sesuai adalah persamaan yang menghubungkan pengaruh konsentrasi kitosan pada kecepatan pengadukan tetap. Sedangkan persamaan yang dihasilkan untuk memprediksikan ukuran diameter mikrokapsul berdasarkan perubahan kecepatan pengadukan pada konsentrasi kitosan tetap tidak dapat digunakan, karena menghasilkan eror yang cukup besar.

\section{UCAPAN TERIMAKASIH}

Ucapan terima kasih ini disampaikan untuk Kementerian Riset, Teknologi dan Pendidikan Tinggi Republik Indonesia (KEMENRISTEK DIKTI RI) atas Beasiswa Pendidikan Pascasarjana Dalam Negeri (BPPDN) yang diberikan, dan juga Departemen Teknik Kimia, Universitas Gadjah Mada atas fasilitas laboratorium sehingga penelitian ini dapat diselesaikan dengan baik.

\section{DAFTAR PUSTAKA}

Anisa, I.N., and Nour, H., 2010. Effect of Viscosity and Droplet Diamter on Water-in-Oil Emulsions: An Experimental Study. Engineering and Technology 38(2), 213-216.

Barba, A.A., D'Amore, M., Cascone, S., Lamberti, G., and Titomanlio, G., 2009. Intensification of Biopolymeric Microparticles Production by Ultrasonic Assisted Atomization. Chemical Engineering and Processing: Process Intensification 48(10), 1477-1483.

Campos, E., Coimbra, P., and Gil, M.H., 2013. An Improved Method for Preparing Glutaraldehyde Cross-Linked Chitosan-Poly(vinyl Alcohol) Microparticles. Polymer Bulletin 70(2), 549-561.

Dalmoro, A., D’Amore, M., and Barba A.A., 2013. Droplet Size Prediction in the Production of Drug Delivery Microsystems by Ultrasonic Atomization. Translational medicine @ UniSa 7(2), 6-11.

Dhakar, R.C., Maurya, S. D., and Saluja, V., 2012. From Formulation Variables To Drug Entrapment Efficiency of Microspheres: A Technical Review. Journal of Drug Delivery and Therapeutics 2(5), 128-133.

Jameela, S.R, and Jayakrishnan, A., 1995. Glutaraldehyde Cross-Linked Chitosan Microspheres as a Long Acting Biodegradable Drug Delivery Vehicle: Studies on the Vitro Release of Mitoxantrone and in Viva Degradation of Microspheres in Rat Muscle. Biomaterials 16(10), 769-775.

Kamarudin, K.S.N., Bhatti, I., Suahadah, S.N., Hamzah, U.N., and MohdFaiz, Z.F., 2010. 
Removal of Carbon Dioxide Using Water-in-Oil Emulsion Liquid Membrane Containing Triethanolamine. Journal of Applied Sciences Research 6(12), 22512256.

Lang, J., 1962. Ultrasonic Atomization of Liquids. The Journal of the Acoustical of America $34(1), 6-8$.

Manjanna, K.M., Shivakumar, B., and Kumar, T.M.P., 2010. Microencapsulation: An Acclaimed Novel Drug-Delivery System for NSAIDs in Arthritis." Critical Reviews $^{\mathrm{TM}}$ in Therapeutic Drug Carrier Systems 27(6), 509-537.

Mitra, A, and Dey, B., 2011. Chitosan Microspheres in Novel Drug Delivery Systems. Indian Journal of Pharmaceutical Sciences 4(73), 355-366.

Mochida, T. 1978. Ultrasonic Atomization of Liquids. Proc. ICLASS, Tokyo, 193-199.

Oboh, G., Ayodele, J.A., Adedayo, O.A. 2012. Antioxidant and inhibitory effect of red ginger (Zingiber officinale var. Rubra) and white ginger (Zingiber officinale Roscoe) on $\mathrm{Fe}^{2+}$ induced lipid peroxidation in rat brain in vitro. Experimental and Toxicologic Pathology 64(1-2), 31- 36

Ofokansi, K. C., Kenechukwu, F.C., Isah, A.B., and Okigbo, E.L., 2013. Formulation and Evaluation of Glutaraldehyde-Crosslinked Chitosan Microparticles for the Delivery of Ibuprofen. Tropical Journal of Pharmaceutical Research 12(1), 19-25.

Rajan, R., and Pandit. A.B., 2001. Correlations to Predict Droplet Size in Ultrasonic Atomisation. Ultrasonics 39(4), 235-255.

Sari, D.K, and Lestari, R.S.D., 2015. Pengaruh Waktu dan kecepatan Pengadukan Terhadap Emulsi Minyak Biji Matahari (Helianthus Annuus L.) dan Air. Jurnal Integrasi Proses 5(3), 155-159.

Shaikh, J., Bhosale, R., Singhal, R. 2006. Microencapsulation of black pepper oleoresin. Food Chemistry 94(1), 105-110

Yeh, H.Y., Chuang, C.H., Chen, H.C., Wan, C.J., Chen, T.L., Lin, L.Y. 2014. Bioactive components analysis of two various gingers (Zingiber officinale Roscoe) and antioxidant effect of ginger extracts, LWT - Food Science and Technology 55(1), 329-334

Zlokarnik, M., 2001. Dimensional Analysis and Scale-up in Theory and Industrial Application. Journal of Liposome Research 11(4), 269-307. 